Received: 08 March 2021

Accepted: 09 June 2021

Online: 16 June 2021

Authors:

A. Singh $₫$, V. Kumar, B. P. Dhyani,

U. P. Shahi

Department of Soil Science and Agricultural

Chemistry, SardarVallabhai Patel University of

Agriculture and Technology,

Meerut, 250110 (U.P.), India

A. Singh $₫$

Department of Agricultural Biotechnology,

SardarVallabhai Patel University of Agriculture

and Technology,

Meerut, 250110 (U.P.), India

V. Rajput

Academy of Biology and Biotechnology,

Southern Federal University,

Rostov-on-Don, Russia

$\bigotimes 9738$ aksingh@gmail.com, intmsc.abhi@gmail.com

Emer Life Sci Res (2021) 7(1): 56-62

E-ISSN: 2395-6658

P-ISSN: 2395-664X

DOI: https://doi.org/10.31783/elsr.2021.715662

\section{Review Article \\ Biochar role in the sustainability and management of soil}

\author{
Akansha Singh, Abhishek Singh, Vishnu Rajput, Vipin Kumar, B. P. \\ Dhyani, U. P. Shahi
}

\begin{abstract}
Agriculture is the most active ecological system in the world where the losses are more than the gains. The soils under agriculture are more exhausted and are having a lower organic matter due to continuous loss than the soils of other ecological systems. The solution for this frequent loss of organic matter can be biochar. The biochar acts as a rich source of organic matter to these soils and acts as a long-term reservoir of carbon. There are three functions of biochar for which its use has been highly promoted over the last few years which includes mitigating climate change by carbon sequestration into the soils, enhancing crop yields, and improving soil structure and functions. It can be produced from various agricultural by-products at different temperatures through the pyrolysis method. The study of biochar properties and the characterization of their effect on soil properties must be done. The methods like Diffuse Reflectance Infrared Fourier Transform Spectroscopy (FTIR), Energy-Dispersive X-ray Spectroscopy (EDX), etc are to be used for the physical identification of biochar. Other properties of biochar and its influence on various soil components and properties like $\mathrm{pH}, \mathrm{EC}$, organic carbon, etc. under its long-term field usage will be discussed in this review.
\end{abstract}

Keywords biochar, pyrolysis, Energy-Dispersive X-ray Spectroscopy (EDX), agriculture, carbon sequestration

\section{Introduction}

The world population has surpassed 7.8 billion and projected to reach 9.7 billion by the year 2050 and restricted agricultural land area for food production of increasing population is a chief concern [1]. To increase food production, new technology is needed in the agricultural field to fill the gap between demand and supply [2]. Agricultural soils are having a relatively smaller proportion of soil carbon pool [3]. For the production of a larger amount of crops, humans are using a larger amount of fertilizer which reduced soil fertility and excess use of fertilizer reduced soil fertility and architecture [1]. For the solution of this problem, biochar has a potential approach. Biochar is a high carbon material produced from the pyrolysis of biomass. It can be called Black Gold for agriculture [4].

Various char or charcoals like materials present in soil are considered as a pool of soil organic carbon [5]. High fertility soils of Amazon were created by pre-Columbian indigenous people of Amazon through the slash and char process called terra preta. These soils have a high content of carbon with its low turnover rate and higher soil persistence therefore the soils of Amazon till now are among the most fertile land of the world. The plants do the process of photosynthesis which reduces the atmospheric carbon dioxide into 
carbohydrate carbon, this stores the carbon into plant biomass which doesn't rapidly decompose when goes into the soil [6]. Therefore, the plant biomass when pyrolyzed leads to a decrease in the rate of its decomposition process in the soils which leads to an increase in its residence time into the soils. The residence time of biochar is in the range of 100 to 1000 years in the soil [4]. The assumption also supports that $80 \%$ of biochar will remain in the soil even after the 100 years of its introduction. The preparation of biochar must be done from the crop residues [3], so that it may lead to an increase the soil fertility and also proves as an intelligent way to recycle organics into the soil as well as effectively reducing $\mathrm{CO} 2$ emission from the soils. The study of certain cases of mean residence time (MRT) of biochar material is present in Table 1 .

Table 1. Mean residence time (MRT) of biochar in various soils [7].

\begin{tabular}{|l|l|l|l|}
\hline SN. & \multicolumn{1}{|c|}{ Place of application } & \multicolumn{1}{|c|}{ Biochar source } & \multicolumn{1}{|c|}{$\begin{array}{c}\text { Mean residence time } \\
\text { (MRT) of biochar } \\
\text { (yrs.) }\end{array}$} \\
\hline 1. & Colombia (savanna) & Charred mango wood & 3,624 \\
\hline 2. & $\begin{array}{l}\text { Thailand and the Philippines } \\
\text { (rice paddies) }\end{array}$ & Charred rice husks & $>1,000$ \\
\hline 3. & $\begin{array}{l}\text { Los Banos, Philippines } \\
\text { (rice paddies) }\end{array}$ & Charred rice husks & 100 to 1000 years \\
\hline 4. & Russia (steppe) & Naturally-occurring fire & Turnover time 293 \\
\hline 5. & Kenya (cropland) & $\begin{array}{l}\text { Slash-and-burn conversion } \\
\text { from forest to cropland }\end{array}$ & 8.3 \\
\hline
\end{tabular}

According to the norms of the International Biochar Initiative (IBI) biochar is a material having the molar ratio of $\mathrm{H}$ to organic $\mathrm{C}$ up to 0.7 [8]. The IBI has defined three classes based on the carbon content of biochar. These include Class 1 biochar which contains ( $\geq 60 \%$ carbon), Class 2 biochar (30 to 60\% carbon), and Class 3 biochar (10\% to 30\% carbon) [9], while European Biochar Certificate (EBC) states that the biochar must have minimum 50\% stable organic carbon in it. The Climate Trust, a US-based non-profit organization written in "climate solutions for governments, utilities, and large businesses" that "at its maximum sustainable potential, biochar could reduce annual global GHG emissions by $12 \%$ ". There are three functions of biochar for which its use has been highly promoted over the last few years which states mitigating climate change by carbon sequestration into the soils, enhancing crop yields, and improving soil structure and functions (Figure 1).

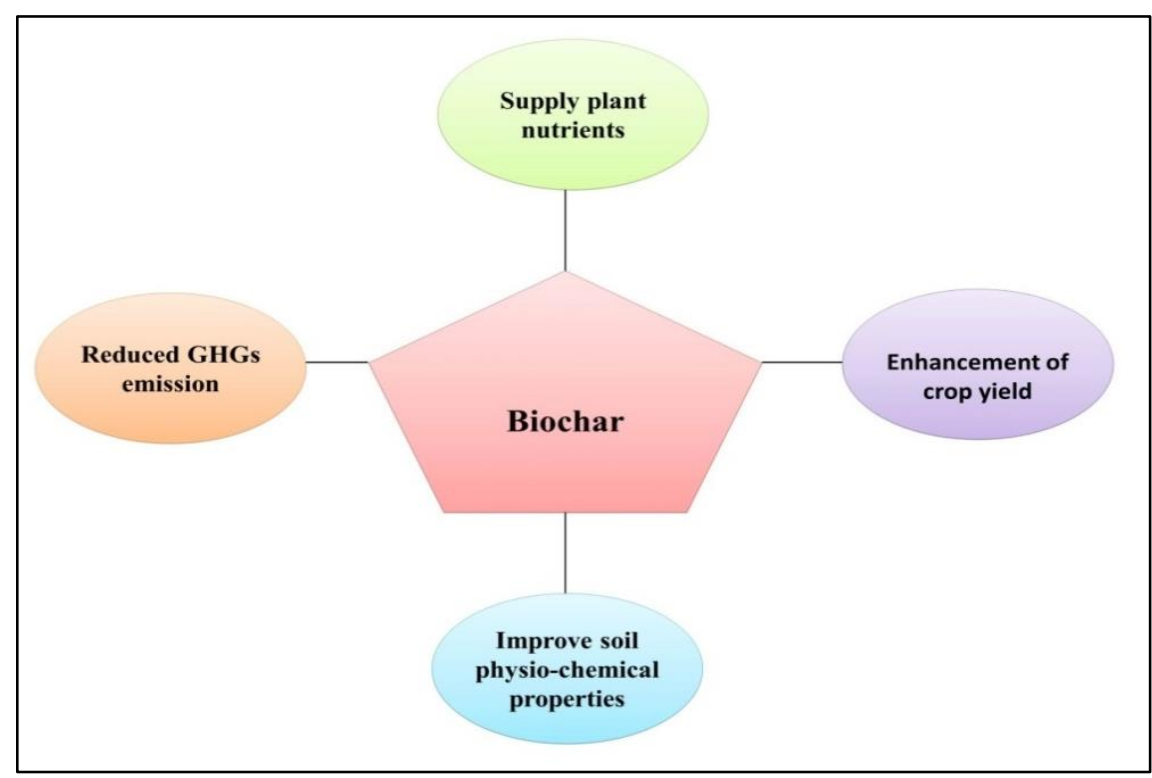

Figure 1. Schematic diagram of application of biochar 


\section{Types of biomass used for biochar production}

Biochar can be produced from a range of organic materials under different conditions, showing variable properties [10]. The currently used feedstock at a commercial scale and for different research facilities may include wood chips, wood pellets, tree bark, and agricultural wastes including crop residues like straw, nutshells, rice hulls, switchgrass, etc. The organic wastes including paper sludge, distillers grain, sugarcane bagasse, olive waste use of chicken litter proposed by Das et al., [11] and other biomass are dairy manure, as well as sewage and sludge. The agricultural waste biochar does not cause any notable greenhouse gas (GHG) emissions. There are a considerably higher yield and porosity of biochar derived from the biomass having more lignin and lesser cellulose [12].

\section{Preparation methods for biochar}

The conversion of biomass into biochar takes place by the use of pyrolysis methods (Figure 2).The pyrolysis of waste biomass avoids the production of greenhouse gases like $\mathrm{CO} 2$ and $\mathrm{N} 2 \mathrm{O}$ and also retains half of the carbon fixed by plants during photosynthesis. The biomass is helpful in the formation of biochar by slow or fast pyrolysis process and it also produces bioenergy as a byproduct. Bioenergy serves as an alternative form of fossil energy with low $\mathrm{CO} 2$ emissions after combustion. The production of $35 \%$ biochar by pyrolysis, a maximum energy output of $8.7 \mathrm{MJ} \mathrm{kg}^{-1}$ has been recorded in the form of bioenergy like liquid fuels [13]. The biochar is produced by the thermal decomposition of waste biomass at temperatures between $200-900^{\circ} \mathrm{C}$ in the presence of very little or no oxygen gas [14]. There are three types of pyrolysis fast, intermediate, and slow according to the residence time of the biomass and the temperature used for this process.

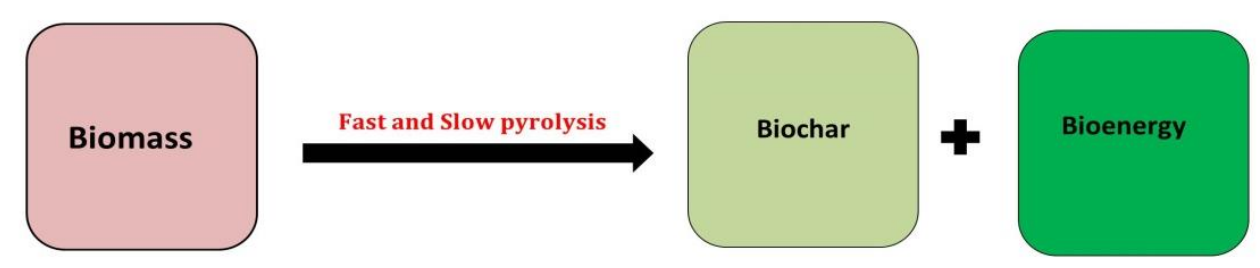

Figure 2. Diagram of preparation methods for biochar

\section{Characterization and properties of biochar}

The surface chemistry of biochar can be examined in a more detailed form by using multiple techniques like Diffuse Reflectance Infrared Fourier Transform Spectroscopy (FTIR), Energy-Dispersive X-ray Spectroscopy (EDX), X-ray photoelectron spectroscopy (XPS), near-edge X-ray absorption fine structure (NEXAFS) spectroscopy [15]. These methods are useful in getting qualitative information about the aging and functionalization of biochar [3]. The physical structure of biochar can be described by scanning electron microscopy (SEM).The physicochemical properties of biochar vary with the temperature at which it forms and the type of feedstock involve in its production. Most of the biochar is produced at the temperature between $300^{\circ} \mathrm{C}$ to $500^{\circ} \mathrm{C}$ possess alkaline $\mathrm{pH}$ [16] and depending on the type of feedstocks also the biochar prevails $\mathrm{pH}$ in the range of 6.1 to 11.6 which again is alkaline. This alkaline character of biochar is due to the presence of carbonates and alkaline elements such as $\mathrm{Na}, \mathrm{K}, \mathrm{Ca}$, and $\mathrm{Mg}$ present, which forms during thermochemical conversion of the biomass. The other properties of biochar due to its alkaline nature are the high total carbon content which is reflected in C: $\mathrm{N}$ ratio of $200: 1$ and lower total nitrogen $\left(1.3 \mathrm{~g} \mathrm{~kg}^{-}\right.$ $\left.{ }^{1}\right)$ [17]. The type of feedstock used for the biochar also affects the energy content of biochar which may range from 30 to $35 \mathrm{MJ} \mathrm{kg}^{-1}$ [18]. The Ash content of this black material also increases with increasing temperature [3]. High microbial activity leads to diminishing the content of soil organic matter but for biochar, this is not the case because the rate of stabilization of this substrate is higher than the ordinary 
organic matter in the soil.The total pore space or total pore volume in biochar is classified under micropores (pores having an internal diameter of $<2 \mathrm{~nm}$ ), mesopores (pores having an internal diameter in the range of $2 \mathrm{~nm}$ to $50 \mathrm{~nm}$ ), and macropores (pores having an internal diameter of $>50 \mathrm{~nm}$ ) [19]. The micropores present in the biochar mainly contribute to its surface area. While on the other hand macropore present in it acts as a habitat for a cluster of the microbial population present in the soil like bacteria, fungi, actinomycetes, and lichens $(0.5 \mu \mathrm{m}$ to $5 \mu \mathrm{m})$.

\section{Effect of biochar on soil components and properties Effect on soil components}

The biochar created at low temperatures is having the ability to control the release of fertilizer nutrients. The plots amended with biochar and additional NPK prove to sustain a higher yield of the crop compared to the control plot [3]. In Indonesia, the yield of maize and peanut plants got enhanced by the addition of bark charcoal when combined with nitrogen fertilizers in the field [20]. The semi-arid soils in Australia also showed positive results with biochar in combination with fertilizers for crop yields during pot trials [17]. Biochar has an affinity for organic compounds so it helps in the sorption of toxic products from wastewater treatment. It also helps in increasing nutrient use efficiency of plants as well as enhancing plant growth and also reduces the emission of nitrous oxide from soils.

\section{Effect on soil properties}

Scientists had admitted that the application of biochar considerably improves soil properties. There have been seen changes in various soil chemical properties due to the application of different rates of biochar. After the application of biochar, soil acidity was also reduced considerably and the essential mineral uptake increased together with its effect in the upcoming season as well. Globally, a considered fact was there that biochar application improves the soil $\mathrm{pH}$ its water-holding capacity as well as an affinity for micro or macro plant nutrients [21]. The changes due to various rates of biochar application in the soils affecting soil properties were reflected in the research of Chan et al., [17] in Table 2.

\section{Effect on soil physical properties}

The increase in aeration and water holding capacity [22] of different soils is being observed with the use of biochar. The water holding capacity of the soil is increased by biochar addition so it may help to reduce wilting of crops at higher temperature regions, where evapotranspiration rates may also be higher [23]. In an experiment by Basso et al., [24] the use of flash pyrolyzed biochar in the sandy soils leads to an increase in soil water holding capacity up to $23 \%$ compared to that of control. The high adsorption capacity and porous structure of biochar lead to an increase in soil water holding capacity. As said by Glaster et al., [25] the water retention in terra preta was $18 \%$ higher than the soil where the charcoal is absent. As with the application of organic matter, the decrease in bulk density and the same was observed in the case of biochar [22]. Akhtar et. al., [4] reported that the addition of biochar leads to a decrease in soil bulk density from 1.63 to $1.54 \mathrm{~g} \mathrm{~cm}-3$. The specific surface area of biochar increases with the increase in temperature due to the formation of micropores and the abundance of the carboxylic group on those surfaces. There may also be a short-lived direct effect of biochar on soil texture because with time the biochar is further divided into a smaller-sized silt-sized particle by abrasion, shrinking and swelling, or freezing and thawing.The soil structure also shows remarkable changes with the addition of biochar uprooting of plants is easy in amended soils compared to non-biochar amended soils. If we talk about soil color, due to the addition of biochar the soil color becomes darker than normal mineral soil. Darker soils absorb more solar energy and display higher soil temperatures which eventually accelerate nutrient cycling and also extend the growing season in temperate regions. On a large spatial scale, it can be seen that the addition of biochar leads to potentially reduce the albedo of the earth's surface [3].

\section{Effect on soil chemical properties (pH, EC, CEC and Organic Carbon)}

In the pot trial conducted on radish using biochar, there is an increase in soil $\mathrm{pH}$ and organic carbon [17]. Most of the time with the application of biochar @ of $30 \mathrm{Mg} \mathrm{ha}^{-1}$ there is an increase in $\mathrm{pH}$ of soil by $0.5-1$ 
Table 2. Effect of various rates of biochar on various soil physicochemical properties [13]

\begin{tabular}{|l|c|c|c|c|c|}
\hline \multicolumn{1}{|c|}{ Biochar rate (t/ha) } & $\mathbf{0}$ & $\mathbf{1 0}$ & $\mathbf{5 0}$ & $\mathbf{1 0 0}$ & $\begin{array}{c}\text { Significance } \\
\text { level }\end{array}$ \\
\hline $\mathbf{p H}$ & 4.77 & 4.75 & 5.38 & 5.99 & $\mathrm{P}<0.001$ \\
\hline $\mathbf{C ~}(\mathbf{g} / \mathbf{k g})$ & 21.6 & 27.0 & 43.4 & 64.6 & $\mathrm{P}<0.001$ \\
\hline Total N (g/kg) & 1.7 & 1.4 & 1.5 & 1.6 & $\mathrm{n} . \mathrm{s}$. \\
\hline Ex. Na (cmol/kg) & 0.60 & 0.58 & 0.74 & 0.84 & $\mathrm{P}<0.001$ \\
\hline Ex. K(cmol/kg) & 0.24 & 0.40 & 0.92 & 1.60 & $\mathrm{P}<0.001$ \\
\hline Ex. Ca (cmol/kg) & 5.50 & 5.18 & 5.58 & 6.30 & $\mathrm{P}<0.001$ \\
\hline Ex. Mg (cmol/kg) & 1.84 & 1.70 & 1.86 & 1.88 & $\mathrm{P}<0.01$ \\
\hline Ex. Al(cmol/kg) & 0.25 & 0.23 & 0.10 & 0.10 & $\mathrm{P}<0.001$ \\
\hline eCEC $(\mathbf{c m o l} / \mathbf{k g})$ & 8.42 & 8.08 & 9.10 & 10.60 & $\mathrm{P}<0.001$ \\
\hline Colwell P & 23.8 & 26.6 & 32.6 & 40.8 & $\mathrm{P}<0.001$ \\
\hline $\begin{array}{l}\text { Field Capacity } \\
\text { (kg/100 } \mathbf{~ k g ) ~}\end{array}$ & 0.255 & 0.244 & 0.270 & 0.320 & $\mathrm{P}<0.001$ \\
\hline
\end{tabular}

unit [8]. If the $\mathrm{pH}$ is in the low range so it can limit plant growth by modifying the dynamics of crop nutrients, hence the addition of biochar is particularly beneficial in acidic soils. There is a significant increase in EC of the soil after the application of BC which was produced from maize stalk. HernandezSoriano and Jimenez-Lopez [26] stated that BC contributes significantly to soil carbon storage, with the addition of $\mathrm{BC}$ there will be a spatial reorganization of $\mathrm{C}$ within the soil particles. The soil respiration is lowered in the soil amended with BC compared to soil amended with other residues. An increase in CEC with relation to nutrient cycling can be seen as the long-term significant effect of biochar on soil biogeochemical processes.

\section{(A) Effect of biochar on soil phosphorus}

The application of biochar to soil increases the retention of phosphorus while some studies suggested that the availability of phosphorus in soil is influenced by the type of soil. The soils enriched with BC influences greater $\mathrm{P}$ availability therefore the root hairs development may get inhibited [27]. It has been found that the presence of multivalent cations such as $\mathrm{Al}^{3+}, \mathrm{Fe}^{3+}, \mathrm{Ca}^{2+}$, and $\mathrm{Mg}^{2+}$ in the biochar promotes the formation of poorly soluble phosphate compounds. Gondek et al., [28] the content of total phosphorus in soils increases with applied $\mathrm{BC}$, without considering the source from which the $\mathrm{BC}$ is prepared. This long-lasting availability due to persistent phosphorus bonds present in the $\mathrm{BC}$ leads to the slower release of phosphorus to plants and also reduces $\mathrm{P}$ losses through leaching in soils.

\section{(B) Effect of biochar on soil nitrogen (N)}

Biochar if applied in soils with nitrogenous fertilizers leads to improve soil properties together with nitrogen use efficiency [17]. Biochar if applied alone can reduce the availability of nitrogen in soil due to its sorption over its surfaces. The addition of biochar into the soil leads to an increase in $\mathrm{C}$ : $\mathrm{N}$ ratio which causes $\mathrm{N}$ immobilization into the soil therefore reduces $\mathrm{N}$ uptake to the crop plants. A pot study with maize plants shows higher biological nitrogen fixation due to the use of biochar in that study [29].

\section{(C) Effect of biochar on soil microbial population}

In terra preta soils where biochar was highly aged and there appears a distinct microbial community structure [30]. The enhanced plant growth was recorded in various works of literature due to stimulation of arbuscular mycorrhizal fungi using biochar [30-31]. The pyrolysis condensates and labile components of biochar in the soil are useful for promoting the microbial responses in the short term.

\section{Conclusion}

The above study regarding the black gold biochar and its soil behavior proves that it is a very young field of research. Therefore, initially, we need a systematic research program that will investigate the stability of 
biochar, represents various feedstocks and production methods, across the climate and soil gradients. It has also been proved that it has the potential to improve various soil properties together with sustainable environmental growth. A range of materials can be used in its preparation and at different pyrolysis temperatures one can prepare it even in your backyard or on your farm. The stated chemical and physical properties of biochar reveal the infrastructure of biochar and acts as a promotive vision for its use in soil application to endure its advantage for enhancing soil chemical and physical properties. As we can see that the large surface area and porosity raise the soil water holding capacity and nutrient absorption. The research must be done in every aspect of biochar application rates, pyrolysis temperature, feedstock to be used and in which soil up to what extent its use is feasible or not.

\section{References}

[1] A. K. Singh, V. Rajput, A. K. Singh, R. S. Sengar, R. K. Singh and T. Minkina (2020). Transformation techniques and their role in crop improvements: A global scenario of GM crops. Elsevier, pp 515-542.

[2] A. Singh, V. Rajput, R. Mehrotra, N. Pal, V. K. Singh, A. V. Chokheli and R. K. Singh (2021). Sustainable Soil Fertility Management, Nova Science Publishers.

[3] S. P.Sohi, E. Krull, E. Lopez-Capel and R. Bol (2010). A review of biochar and its use and function in soil. Adv. in Agron., 105: 47-82.

[4] S. S. Akhtar, M. N. Andersen and F. Liu (2015). Residual effects of biochar on improving growth, physiology and yield of wheat under salt stress. Agril. Water Mgt., 158: 61-68.

[5] J. O. Skemstad, P. Clarke, J. A. Taylor, J. M. Oades and S. G. Mcclure (1996). The chemistry and nature of protected carbon in soil. Soil Res., 34: 251- 257.

[6] A. I. Belyanovskaya, B. Laratte, V. D. Rajput, N. Perry and N.V. Baranovskaya (2020). The innovation of the characterisation factor estimation for LCA in the USETOX model. J. Clean. Prod., doi: 10.1016/j.jclepro.2020.122432.

[7] N. P. Gurwick, L. A. Moore, C. Kelly and E. Patricia (2013). A systematic review of biochar research, with a focus on its stability in situ and its promise as a climate mitigation strategy. PloSone. doi: 10.1371/journal.pone.0075932.

[8] S. Shackley, S. Sohi, R. Ibarroa, J. Hammond, O. Masek, P. Brownsort, A. Cross et al., (2013). Biochar, tool for climate change mitigation and soil management In Geoengineering responses to climate change, Springer, New York, NY, pp73-140.

[9] IBI-International biochar initiative (2014). http://www.biocharinternational.org/sites/default/files/IBI Biochar Standards V2\%200 final 2014.pdf

[10] M. Guerrero, M. P. Ruiz, M. U. Alzueta, R. Bilbao and A. Millera (2005). Pyrolysis of eucalyptus at different heating rates: studies of char characterization and oxidative reactivity. J. Analy. And Appli. Pyro., 74: 307-314.

[11] K. C. Das, M. Garcia-Perez, B. Bibens and N. Melear (2008). Slow pyrolysis of poultry litter and pine woody biomass: Impact of chars and bio-oils on microbial growth. J. Environ. Sci. Health A, 43: 714724.

[12] O. D. Nartey and B. Zhao (2014). Biochar preparation, characterization, and adsorptive capacity and its effect on bioavailability of contaminants: an overview. Adv. Mater. Sci. Eng., doi: $10.1155 / 2014 / 715398$.

[13] D. Woolf (2008). Biochar as a soil amendment: A review of the environmental implications. https://orgprints.org/id/eprint/13268/1/Biochar_as_a_soil_amendment_-_a_review.pdf.

[14] A. Demirbas and G. Arin (2002). An overview of biomass pyrolysis. Energy Sources, 24: 471-482.

[15] J. Lehmann, J. Gaunt and M. Rondon (2006). Bio-char sequestration in terrestrialecosystems-A review. Mitig. Adapt. Strateg. Glob. Chang., 11: 403-427.

[16] I. I. Manolikaki, A. Mangolis and E. Diamadopoulos (2016). The impact of biochars prepared from agricultural residues on phosphorus release and availability in two fertile soils. J. Envi. Mgt., 181: 536543. 
[17] K. Y. Chan, L. Van-Zwieten, I. Meszarso, A. Downie and S. Joseph (2008). Agronomic values of greenwaste biochar as a soil amendment. Soil Res., 45: 629-634.

[18] D.-J. Ryu, R.-G. Oh, Y.-D. Seo, S.-Y. Oh and K.-S. Ryu (2015). Recovery and electrochemical performance in lithium secondary batteries of biochar derived from rice straw. Environ. Sci. Pollut. Res., 22: 10405-10412.

[19] P. L. Llewellyn, F. Rouquerol, J. Rouquerol and K. Sing (2000). Adsorption by powders and porous solids. Academic Press, London. pp421-428.

[20] S. Yaman (2004). Pyrolysis of biomass to produce fuels and chemical feedstocks. Energy Convers. Manag., 45: 651-671.

[21] N. L. Panwar, A. Pawar and B. L. Salvi (2019). Comprehensive review on production and utilization of biochar. SN Applied Sciences, doi: 10.1007/s42452-019-0172-6.

[22] S. D. C. Case, N. P. McNamara, D. S. Reay and J. Whitaker (2012). The effect of biochar addition on $\mathrm{N}_{2} \mathrm{O}$ and $\mathrm{CO}_{2}$ emissions from a sandy loam soil-The role of soil aeration. Soil Biol. Biochem., 51: 125134.

[23] D. N. Mulcahy, D. L. Mulcahy and D. Dietz (2013). Biochar soil amendment increases tomato seedling resistance to drought in sandy soils. J. Arid. Environ., 88: 222-225.

[24] A. S. Basso, F. E. Miguez, D. A. Laird, R. Horton and M. Westgate (2013). Assessing potential of biochar for increasing water-holding capacity of sandy soils. GCB. Bioenergy, 5: 132-143.

[25] B. Glaster, L. Haumaier, G. Guggenberger and W. Zech (2001). The 'Terra Preta' phenomenon: a model for sustainable agriculture in the humid tropics. Naturwissenschaften, 88: 37-41.

[26] M. C. Hernandez-Soriano and J. C. Jimenez-Lopez (2012). Effects of soil water content and organic matter addition on the speciation and bioavailability of heavy metals. Sci. Total Environ., 423: 55-61.

[27] M. T. Prendergast-Miller, M. Duvall and S. P. Sohi (2014). Biochar-root interactions are mediated by biochar nutrient content and impacts on soil nutrient availability. Eur. J. Soil Sci. 65: 173-185.

[28] K. Gondek, M. Mierzwa-Herszt, M. Kopeć, J. Sikora, T. Głąb and K. Szczurowska(2019). Influence of Biochar Application on Reduced Acidification of Sandy Soil, Increased Cation Exchange Capacity, and the Content of Available Forms of K, Mg, and P. Pol. J. Environ. Stud., 28: 103-111.

[29] M. A. Rondon, J. Lehmann, J. Ramírez and M. Hurtado (2007). Biological nitrogen fixation by common beans (Phaseolus vulgaris L.) increases with bio-char additions. Biol. Fertil. Soils., 43: 699-708.

[30] K. H. Kim, J.-Y. Kim, T.-S. Cho and J. W. Choi (2012). Influence of pyrolysis temperature on physicochemical properties of biochar obtained from the fast pyrolysis of pitch pine (Pinus rigida). Bioresour. Technol., 118: 158-62.

[31] G. Andrey, V. Rajput, M. Tatiana, M. Saglara, S. Svetlana, K. Igor and T. V. Grigryeva et al., (2019). The role of biochar-microbe interaction in alleviating heavy metal toxicity in Hordeum vulgare L. grown in highly polluted soils. Appl. Geochem., 104: 93-101. 